\title{
Crack Propagation Behavior of Impact Fracture in Case Hardening Steel Subjected to Combined Heat Treatment with Excess Vacuum Carburizing and Subsequent Induction Hardening
}

\author{
Kazuaki OKADA, ${ }^{1,2) *}$ Koji OBAYASHI, ${ }^{1)}$ Yoshikazu TODAKA ${ }^{2)}$ and Nozomu ADACHI ${ }^{21}$ \\ 1) Heat Treatment Engineering Department, Aisin AW CO., LTD., 10 Takane Fujii, Anjo, Aichi, 444-1192 Japan. \\ 2) Department of Mechanical Engineering, Toyohashi University of Technology, 1-1 Hibarigaoka, Tempaku, Toyohashi, Aichi, \\ 441-8580 Japan.
}

(Received on December 29, 2019; accepted on April 27, 2020; J-STAGE Advance published date: July 3, 2020)

\begin{abstract}
The Charpy impact value of case hardening steel subjected to combined heat treatment with excess vacuum carburizing and subsequent induction hardening was evaluated. The purpose of this study is to clarify the relation between the crack propagation behavior and the microstructure in steels having different amounts of retained austenite and cementite. The vacuum carburizing treatment is performed at the hyper-eutectoid composition of 1.3 mass \% C. Three different heating temperatures were chosen for induction hardening in the two-phase (austenite, cementite) region between $A_{\mathrm{cm}}$ and $A_{1}$ to obtain different amounts of retained austenite and cementite. Decreasing the induction heating temperature from $1143 \mathrm{~K}$ to $1043 \mathrm{~K}$, increased crack propagation resistance by around 30\% on average in both the quenched-only and the quenched-and-tempered specimens. The high crack propagation resistance of the samples with the low induction heating temperature was caused by the arrest effect of undissolved $\theta$. By contrast, in the sub-zero treated specimens, crack propagation resistance showed an almost constant value irrespective of the induction heating temperature. That constant propagation resistance was attributed to the repeated bending and branching occurring during crack propagation.
\end{abstract}

KEY WORDS: crack propagation; crack arrest; residual stress; undissolved cementite; retained austenite; Charpy impact value; carburizing steel.

\section{Introduction}

Recent regulations on $\mathrm{CO}_{2}$ emissions and fuel consumption imposed on automobiles have driven the requirements for downsizing automobile components to high levels. Therefore, the gear and shaft parts used for power transmission are required to have higher strength and toughness. In response to these circumstances, we developed a surface hardening treatment that combines vacuum carburizing and subsequent induction hardening. This process was called mild-carburizing. ${ }^{1,2)}$ The mild-carburizing treatment forms a normalized microstructure with the required carbon concentration distribution through vacuum carburizing and subsequent slow cooling. Afterward, the induction heating and water quenching are performed to form a martensite $(\alpha$ ) microstructure.

The vacuum carburizing treatment was performed at the hyper-eutectoid composition to form pearlite and pro-

\footnotetext{
* Corresponding author: E-mail: i28741_Okada@aisin-aw.co.jp
}

eutectoid cementite $(\theta)$. Subsequently, water quenching was performed after induction heating between $A_{1}$ and $A_{\mathrm{cm}}$ in order to control the dispersion of undissolved $\theta$ and the amount of retained austenite $(\gamma)$. Although case hardening steel subjected to excess vacuum carburizing exhibits improved wear resistance and rolling contact fatigue strength due to $\theta$, toughness may decrease. In our previous report, ${ }^{3)}$ the relation between the impact property, the undissolved $\theta$ and the retained $\gamma$ formed by controlling the induction heating temperature of two-phase $(\gamma, \theta)$ for the case hardening steel subjected to this process was investigated. It was shown that the amount of retained $\gamma$ increased with the induction heating temperature, and that crack initiation and crack propagation energies showed a further increase by tempering. Since brittle fractures lead to breakage in a short time once a crack initiates, the crack initiation property becomes important. In addition, a design focused on crack propagation is necessary to ensure even higher levels of safety. Figure 1 shows the definition of impact properties obtained from the load-displacement curve of the instru- 


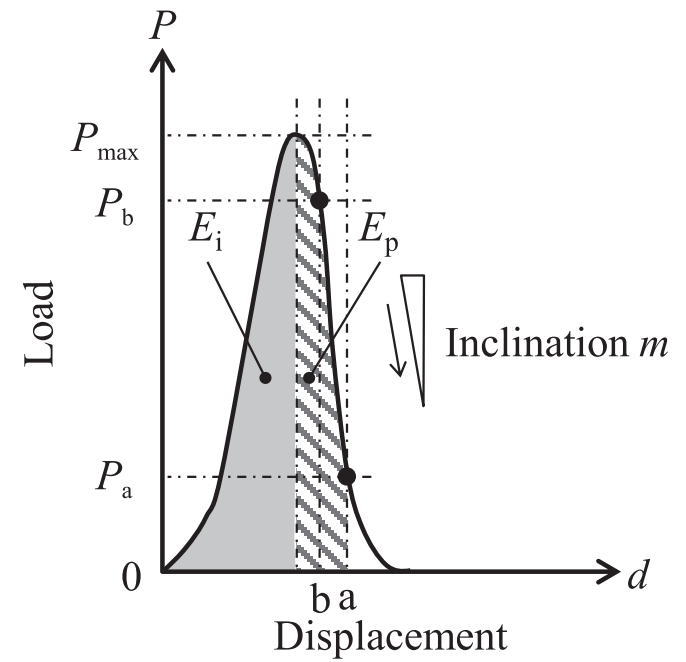

$P_{\max }:$ Maximum load

$E_{\mathrm{i}} \quad$ : Crack initiation energy

$E_{\mathrm{p}} \quad$ : Crack propagation energy

$P_{\mathrm{a}} \quad$ : Load of displacement a

$P_{\mathrm{b}} \quad$ : Load of displacement $\mathrm{b}$

a $\quad: 0.30 \mathrm{~mm}$ from displacement of $P_{\max }$

b $\quad: 0.08 \mathrm{~mm}$ from displacement of $P_{\max }$

Fig. 1. Definition of the crack initiation energy $\left(E_{\mathrm{i}}\right)$, crack propagation energy $\left(E_{\mathrm{p}}\right)$, and the crack propagation resistance $(m)$ determined from the load-displacement curve.

mented Charpy impact test. In our previous report, ${ }^{3)}$ the discussion of the crack propagation behavior focused on the propagation energy $\left(E_{\mathrm{p}}\right)$ which is calculated through integration using the maximum load $\left(P_{\max }\right)$ as the dividing point in the load-displacement curve. Kobayashi et $a l^{4)}$ studied a method for evaluating brittle fracture using the Charpy impact test method. In their evaluation of crack propagation, they focused not only on $E_{\mathrm{p}}$ but also on the loads where the brittle fracture starts and ends in the load-time curve. Based on this previous study, the $E_{\mathrm{p}}$ as defined in Fig. 1 includes both information on the change in $P_{\max }$ and the degree of inclination ( $m$ value) of the load after crack initiation. A high $m$ value means high crack propagation resistance. It is important to separate out the two definitions $\left(E_{\mathrm{p}}, m\right)$ and analyze the detailed behavior of the propagation process in order to obtain the design criteria to improve the $m$ value.

This study uses the instrumented Charpy impact test method to examine propagation behavior after crack initiation in case hardening steels subjected to combined heat treatment with excess vacuum carburizing and subsequent induction hardening. The purpose of this study is to clarify how the dispersion morphology of undissolved $\theta$ in the carburized layer affects the $m$ value.

\section{Experimental Procedure}

The specimens used in this experiment were made of the same material and subjected to the same heat treatment as in our previous report. ${ }^{3)}$ The chemical composition of the case hardening steel used in this study was $0.21 \mathrm{C}, 1.12 \mathrm{Si}$, $0.81 \mathrm{Mn}, 0.020 \mathrm{P}, 0.017 \mathrm{~S}, 0.32 \mathrm{Cr}, 0.17 \mathrm{Mo}[\mathrm{mass} \%]^{3)}$ It is similar to JIS SCM 420, but Si was added to improve temper softening resistance. The steel bar was normalized at $1223 \mathrm{~K}$ for $7.2 \mathrm{ks}$ and machined into the shape with the notch. After the heat treatment, the Charpy impact test specimens were cut out by wire electric discharge machining. The notch face and the other three faces were ground $0.1 \mathrm{~mm}$ from the surface. The notch on the carburized surface was grinded by $0.1 \mathrm{~mm}$ to correct the distorted dimensions in the heat treatment process. Three of the four cut out specimens were used for the impact test, and the remaining one was used to investigate the hardness, microstructure, amount of retained $\gamma$, and residual stress before the test. The Charpy impact test specimens had a shape of $10 \times 10 \times 55 \mathrm{~mm}^{3}$ and a $10 \mathrm{R}$ notch with a notch depth of 2 $\mathrm{mm}$. The carburizing layer was only applied to the notch face of the specimens.

The heat treatment was performed under the conditions shown in Table 1. ${ }^{3)}$ A subsequent heat treatment was performed with or without tempering and with or without sub-zero treatment prior to tempering. A vacuum carburizing furnace was used for the carburizing process. After the specimens were heated to the carburizing temperature $\left(T_{1}\right)$ of $1273 \mathrm{~K}$, the carburizing gas was flowed into the furnace for $2.4 \mathrm{ks}$. Subsequently, the specimens were slowly cooled from $T_{1}$ to room temperature. The carburizing pressure was $250 \mathrm{~Pa}$, and $\mathrm{C}_{2} \mathrm{H}_{2}$ was used as the carburizing gas. The slow cooling rate of $0.5 \mathrm{~K} / \mathrm{s}$ was employed during cooling to $973 \mathrm{~K}$, and nitrogen was used as the cooling gas. Regarding the initial microstructure of the specimen for induction hardening, the surface microstructure was pearlite with pro-eutectoid $\theta$, and the internal microstructure was ferrite $(\alpha)$ and pearlite. After carburizing, the surface $\mathrm{C}$ concentration was 1.3 mass $\% \mathrm{C}$. The total case depth to $0.2 \mathrm{mass} \%$ $\mathrm{C}$ corresponding to the $\mathrm{C}$ concentration in the raw material was $0.8 \mathrm{~mm}$. The induction heating temperatures $\left(T_{2}\right)$ were $1043 \mathrm{~K}$ (Conditions 1, 4, and 7), $1093 \mathrm{~K}$ (Conditions 2, 5, and 8) and $1143 \mathrm{~K}$ (Conditions 3, 6, and 9). For the surface carburizing layer having 1.3 mass $\% \mathrm{C}$, the three $T_{2}$ were chosen from the two-phase $(\gamma, \theta)$ region between $A_{\mathrm{cm}}$ and $A_{1}$ at $50 \mathrm{~K}$ intervals to control the amounts of $\theta$ and retained $\gamma$. For the interior having 0.2 mass $\% \mathrm{C}$, these $T_{2}$ are located at two-phase $(\gamma, \alpha)$ region between $A_{3}$ and $A_{1}$ or the single-phase region above $A_{3}$. Induction heating equipment with an induction frequency of $6.0 \mathrm{kHz}$ was used to increase the temperature up to $T_{2}$ in $10 \mathrm{~s}$. The specimen was kept at $T_{2}$ for a holding time of $8 \mathrm{~s}$ to assure a homogeneous temperature distribution in the sample. A water-soluble polymer whose temperature was controlled at $303 \pm 2 \mathrm{~K}$ was used as the liquid for quenching. Only quenching was performed for conditions $1-3$. For conditions 4-6, tempering was performed at $453 \mathrm{~K}$ for $5.4 \mathrm{ks}$ through furnace heating after applying the heat treatment from conditions $1-3$. Conditions 7-9 used the same quenching and tempering conditions as conditions 4-6, but a sub-zero treatment was performed prior to tempering in liquid nitrogen for $3.6 \mathrm{ks}$.

Cross-sectional microstructure observation was performed on the notch bottom of the specimen, and its cross section was the plane perpendicular to the rolling direction of the material. After polishing the cross section with waterproof abrasive paper \# 120-1 200, mirror finishing was done by buffing using diamond paste (particle diameter: 1.0 $\mu \mathrm{m}$ ) and chemically etched by $5 \%$ nital (nitric acid: $5 \mathrm{ml}$, ethanol: $95 \mathrm{ml}$ ). Thereafter, the microstructure was observed 
Table 1. Conditions of heat treatment. ${ }^{3)}$

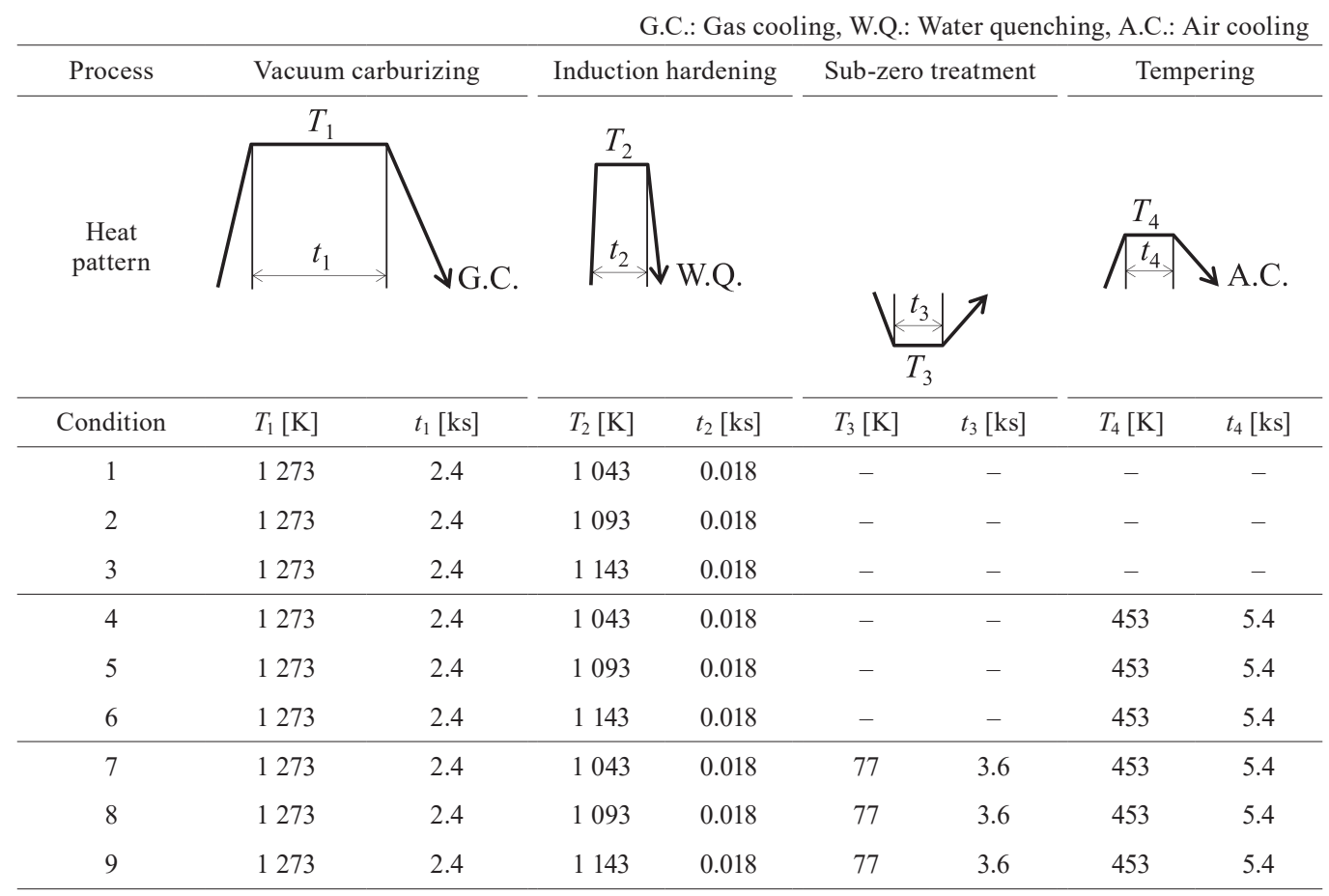

(a)

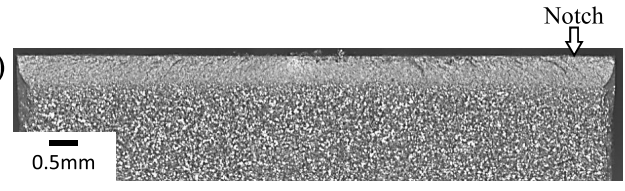

(b)

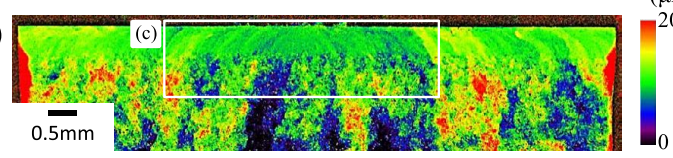

(c)

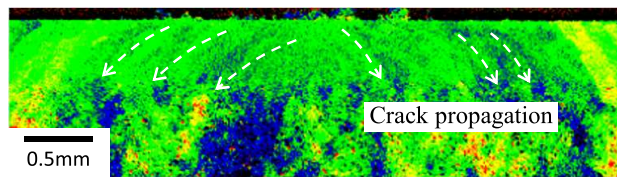

Fig. 2. (a), (b) LSM (laser microscope) micrographs of the fracture surface and the corresponding height maps. (c) High magnification micrograph observed at the rectangle mark in (b). (Online version in color.)

by using a scanning electron microscope (SEM) (S-3400N, Hitachi High-Tech). The amount of retained $\gamma$ and residual stress were measured via X-ray diffractometry using an $\mathrm{X}$-ray diffractometer (PSPC-MSF, Rigaku). $\mathrm{Cr}-\mathrm{K} \alpha$ radiation was used under $40 \mathrm{kV}$ and $40 \mathrm{~mA}$ operation conditions. The volume fraction of retained $\gamma$ was calculated by the ratio of two diffraction peaks: (211) peak for $\alpha$ phase and (220) peak for $\gamma$ phase in the range of $2 \theta: 146^{\circ}-164^{\circ}$ ( $\alpha$ phase) and $124^{\circ}-132^{\circ}$ ( $\gamma$ phase). The residual stress was calculated from the slope of the relationship between $2 \theta$ and $\sin ^{2} \psi$. The range of $2 \theta$ was $140^{\circ}-170^{\circ}$. The diffraction angle $\psi$ was $0^{\circ}-40^{\circ}$. The inverse pole figure (IPF) mapping and phase mapping were measured by using a field emission scanning electron microscope (FESEM) (SU-70, Hitachi High-Tech) equipped with an Oxford Instruments electron backscatter diffraction (EBSD) system. The EBSD measurement was carried out with a step size of $0.05 \mu \mathrm{m}$. The impact value was measured by using an instrumented Charpy impact tester (CHARPAC-500CR, Yonekura). Three specimens were tested for each condition, and the test temperature was 299 $\mathrm{K}$. The fracture surface after the test was observed by using SEM. Figure 2 shows the method for measuring the fracture roughness. The height map of the fracture surface was measured by using a laser microscope (LSM) (OLS4100, Olympus). The region of $0.3 \mathrm{~mm}$ square was measured at three areas for one specimen. The reason for choosing $0.3 \mathrm{~mm}$ square was to obtain a statistically reliable roughness. A crack origin was specified from the radially spread chevron pattern representing the trace of crack propagation. The measured regions were the crack origin and both sides thereof in the carburized surface region. The arithmetical mean height $S a{ }^{5)}$ a 3-dimensional parameter expanded from the roughness 2-dimensional parameter $R a$, ${ }^{6}$ was used as a roughness parameter. It represents the average of the absolute values of height from the average plane in the measured region.

\section{Results}

\subsection{Microstructure before Charpy Impact Test}

Figure 3 shows the cross-sectional SEM microstructure of the surface. The microstructure of the conditions 1,4 , and 7 specimens with the lowest $T_{2}$ had lath $\alpha^{\prime}$ in the grain and pro-eutectoid $\theta$ at the prior austenite grain boundary. In the vicinity of the prior austenite grain boundary, undissolved quasi-lamellar $\theta$ of the initial microstructure pearlite was observed. As $T_{2}$ increased, the formation of a $\mathrm{C}$ solid solution progressed through the decomposition of pro-eutectoid $\theta$, and the formation of $\alpha^{\prime}$ became a mixed microstructure of lath $\alpha^{\prime}$ and lenticular $\alpha^{\prime}$. There was not much difference in the SEM microstructures regardless of whether tempering had been applied. Comparing the microstructures in the condition 6 specimen (without sub- 


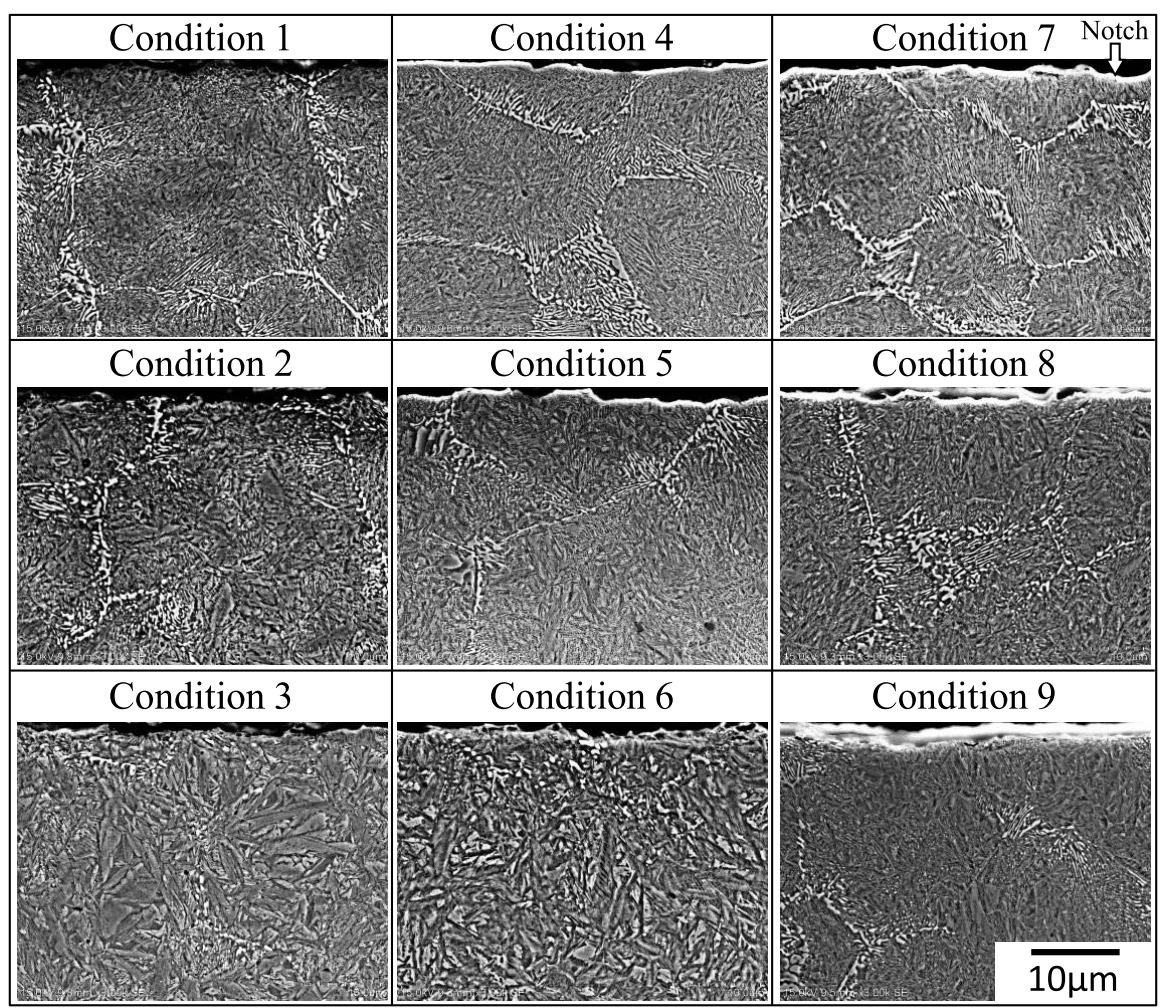

Fig. 3. SEM (scanning electron microscope) micrographs of the specimens cross-sectionally observed at the vicinity of the notch. ${ }^{3)}$

(a)

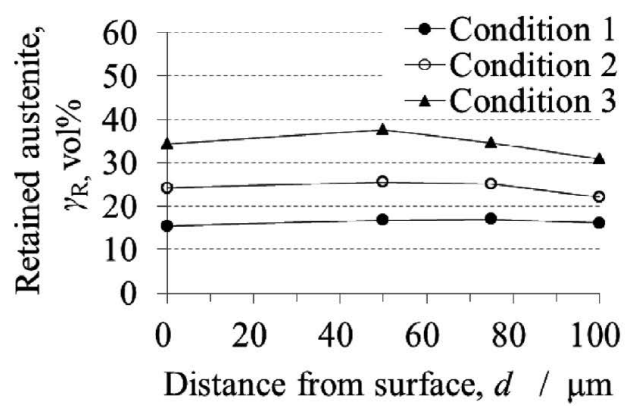

(b)

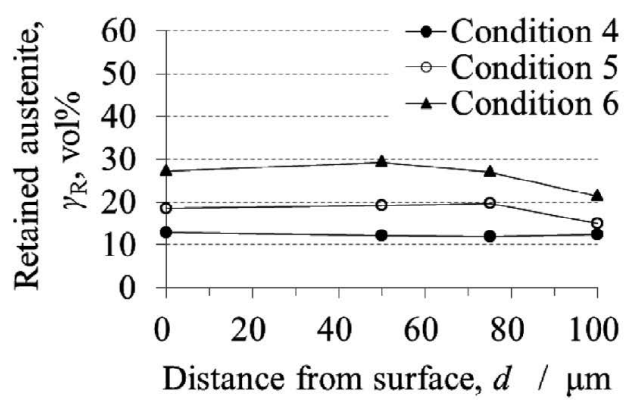

(c)

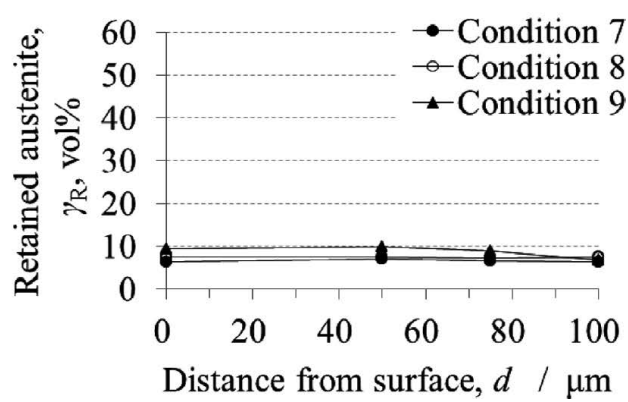

Fig. 4. Depth profiles of the amount of retained austenite in the (a) quenching, (b) tempering and (c) sub-zero treated and tempering specimens. zero treatment) and condition 9 specimen (with sub-zero treatment) with the large amount of $\mathrm{C}$ solid solution, it can be seen that the sub-zero treatment resulted in a formation of fine $\alpha^{\prime}$. This is because the clumped $\gamma$ between $\alpha^{\prime}$ after quenching was transformed into fresh, fine $\alpha^{\prime}$ and subdivided. Figure 4 shows the distribution of the retained $\gamma$ in the vicinity of the specimen notch. The amount of retained $\gamma$ increased with $T_{2}$. With tempering, the amount of retained $\gamma$ decreased by $2-8$ vol $\%$ at the surface in each condition. Further, with the sub-zero treatment, the amount of retained $\gamma$ decreased by $7-18$ vol\% compared to that of the tempered conditions. Figure 5 shows the IPF maps and phase maps for the conditions 6 and 9 specimens. There was almost no difference in the dispersion of the retained $\gamma$. In the phase maps, the volume fractions of retained $\gamma$ in the conditions 6 and 9 specimens were 6 vol\% and 2 vol\%, respectively. In comparison with amounts measured via X-ray diffractometry (Fig. 4), the tendency of the amount to decrease due to the sub-zero treatment was the same. However, the absolute values of volume fraction in the conditions 6 and 9 specimens were 27 vol\% and 9 vol\%, respectively, which differed from the results of phase maps shown in Fig. 5. Tomota et $a l .{ }^{7)}$ compared the volume fraction of retained $\gamma$ for $\mathrm{Mn}-\mathrm{Si}-\mathrm{C}$ steel by various methods. In the same specimen, the amount of retained $\gamma$ measured by using EBSD was about half as low as that measured by X-ray diffraction. This tendency is the same as this study. Tomota et al. have reported several reasons of different values of volume faction of retained $\gamma$ between experimental methods. Among these reasons, it can be presumed that the difference of measurement area between EBSD and X-ray diffraction is possible reason. 


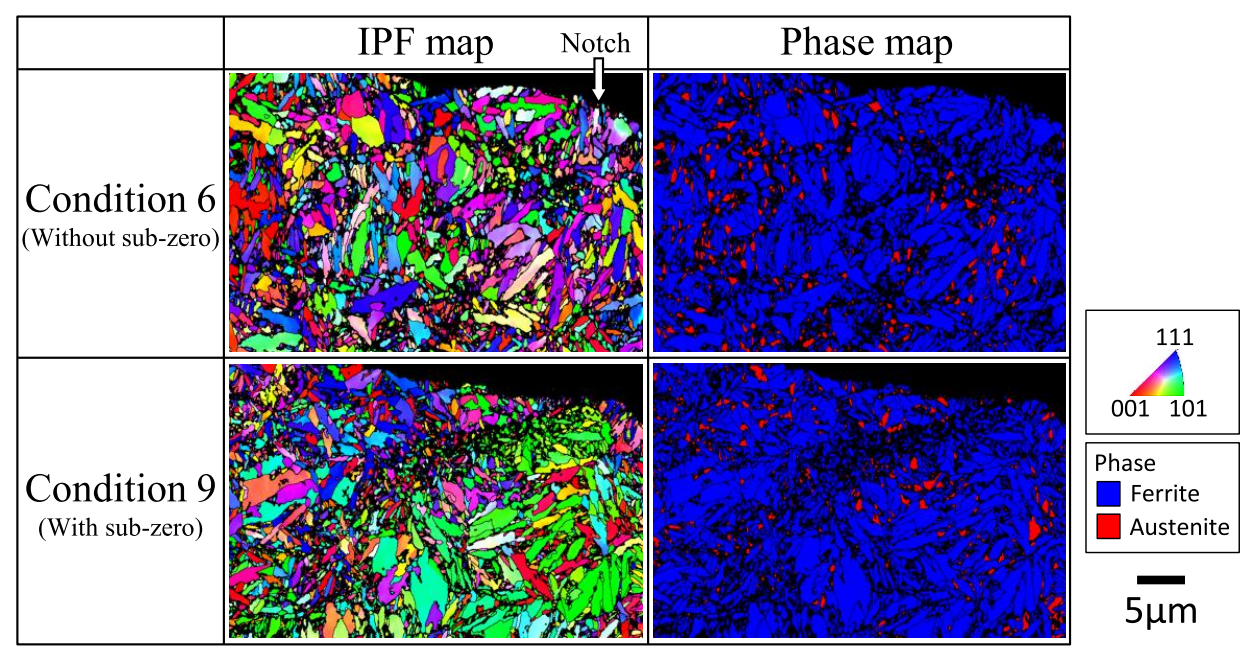

Fig. 5. SEM/EBSD (Electron Back Scatter Diffraction) IPF (Inverse Pole Figure) maps and phase maps at the vicinity of the notch in the conditions 6 and 9 specimens before the Charpy impact test. (Online version in color.)

(a-1)

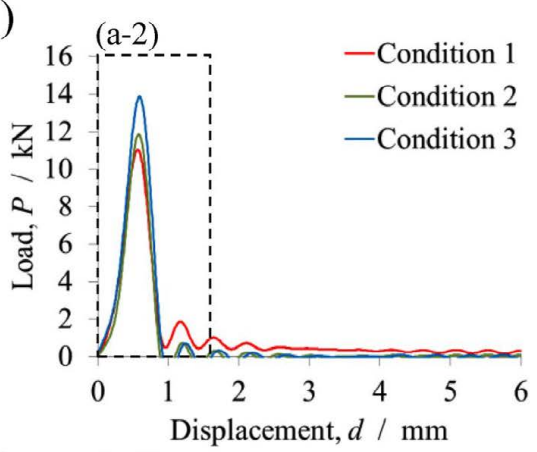

(b-1)
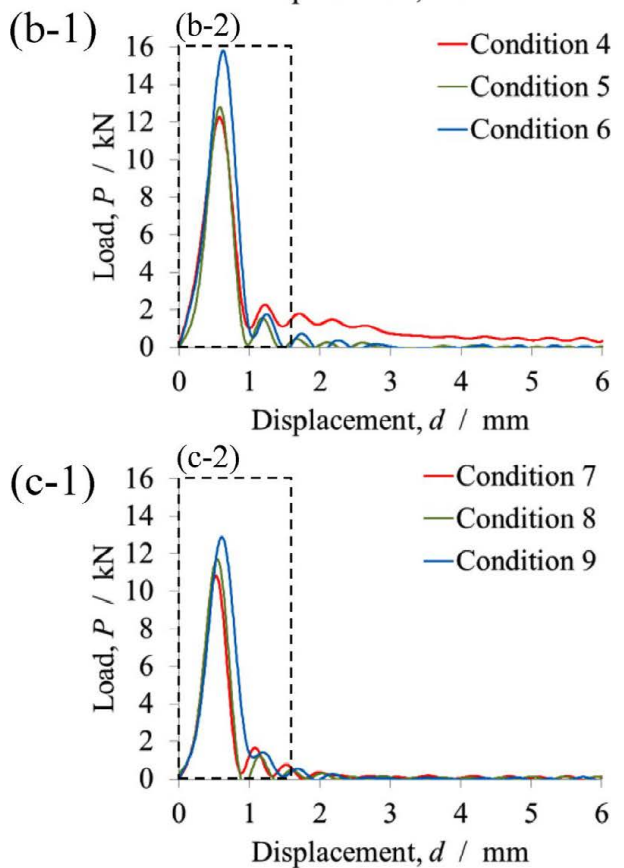

$(\mathrm{a}-2)$

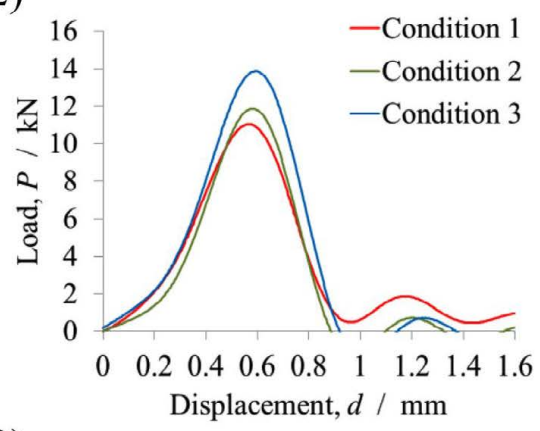

(b-2)

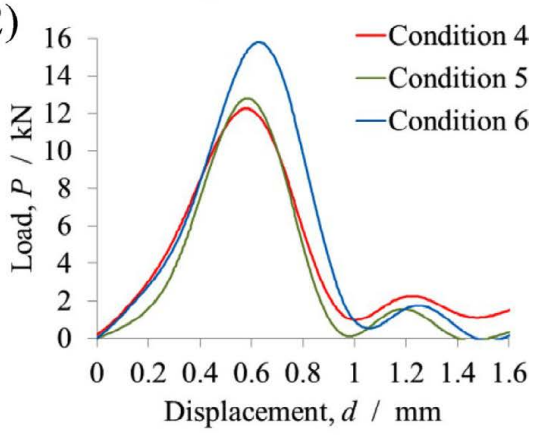

(c-2)

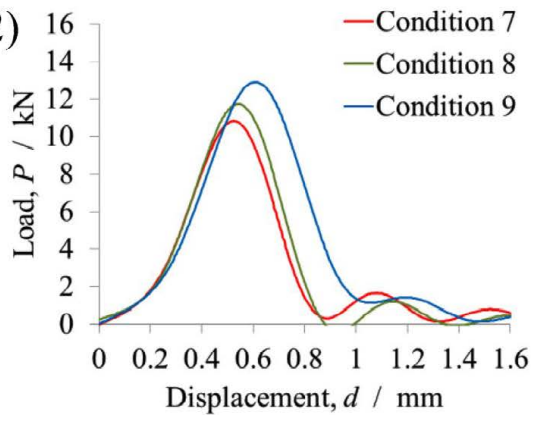

Fig. 6. Load-displacement curves in the (a-1) quenching, (b-1) tempering and (c-1) sub-zero treated and tempering specimens during the instrumented Charpy impact test. (a-2), (b-2) and (c-2) show the enlarged views at the rectangle mark in (a-1), (b-1) and (c-1). (Online version in color.)

\subsection{Result of Charpy Impact Test}

Figure 6 shows the load-displacement curve obtained from the instrumented Charpy impact test. The inclination from the load start to $P_{\max }$ did not differ depending on individual conditions. $P_{\max }$ increased with $T_{2}$. Since the inclination from the load start to $P_{\max }$ was almost the same regard- less of $T_{2}$, the higher $P_{\max }$ indicated higher resistance to crack initiation. The load at a displacement of $1 \mathrm{~mm}$ or more was higher in conditions 1 and 4 than in other conditions. In our previous report, ${ }^{3)}$ the Charpy absorbed energy was evaluated separately for the crack initiation energy and propagation energy. As shown in Fig. 1, the area calculated through 
(a)

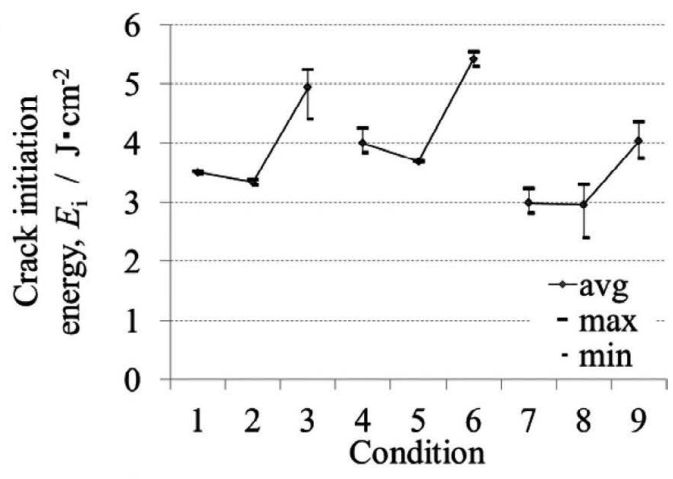

(b)

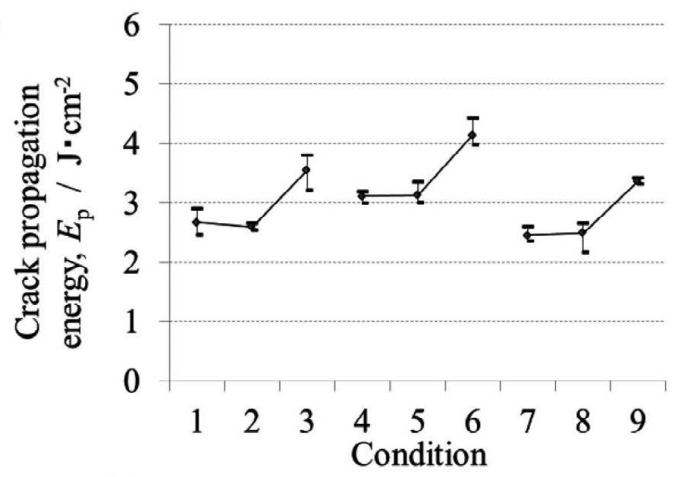

(c)

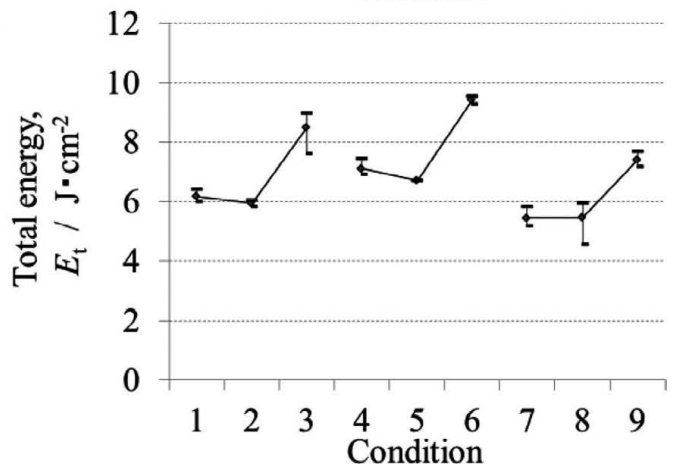

Fig. 7. (a) Crack initiation energy $\left(E_{\mathrm{i}}\right)$, (b) crack propagation energy $\left(E_{\mathrm{p}}\right)$, and (c) total energy $\left(E_{\mathrm{t}}\right)$ in the Charpy impact test. ${ }^{3)}$ integration from the load start to the $P_{\max }$ was defined as the crack initiation energy $\left(E_{\mathrm{i}}\right)$, and that calculated through integration in the displacement range of $0.3 \mathrm{~mm}$ from $P_{\max }$ was defined as the $E_{\mathrm{p}}$ in the load-displacement curve. Then, the $E_{\mathrm{i}}+E_{\mathrm{p}}$ was defined as the total energy $\left(E_{\mathrm{t}}\right)$. The reason for setting the displacement to $0.3 \mathrm{~mm}$ from $P_{\max }$ for the calculation of $E_{\mathrm{p}}$ was to investigate the propagation behavior of the carburizing layer having a hyper-eutectoid composition and a large amount of retained $\gamma$ up to $0.3 \mathrm{~mm}$ from the surface in the $\mathrm{C}$ concentration distribution. ${ }^{3)}$ Figure 7 shows the results of $E_{\mathrm{i}}, E_{\mathrm{p}}$, and $E_{\mathrm{t}} . E_{\mathrm{i}}$ (Fig. 7(a)) showed a sharp increase at $T_{2}$ from $1093 \mathrm{~K}$ (Conditions 2, 5, and 8) to $1143 \mathrm{~K}$ (Conditions 3, 6, and 9), despite showing no clear difference from $1043 \mathrm{~K}$ (Conditions 1, 4, and 7) to $1093 \mathrm{~K}$ (Conditions 2, 5, and 8). The change in $E_{\mathrm{p}}$ with $T_{2}$ showed a similar tendency with $E_{\mathrm{i}}$ (Fig. 7(b)). Therefore, the $E_{\mathrm{t}}$ calculated from $E_{\mathrm{i}}$ and $E_{\mathrm{p}}$ consequently showed the same tendency (Fig. 7(c)). In the comparison of individual heat

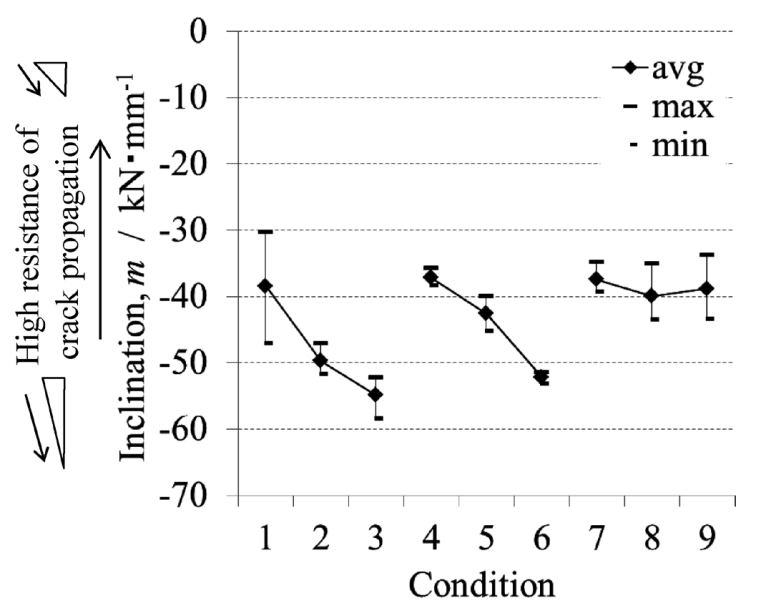

Fig. 8. Crack propagation resistance $(m)$ in the Charpy impact test.

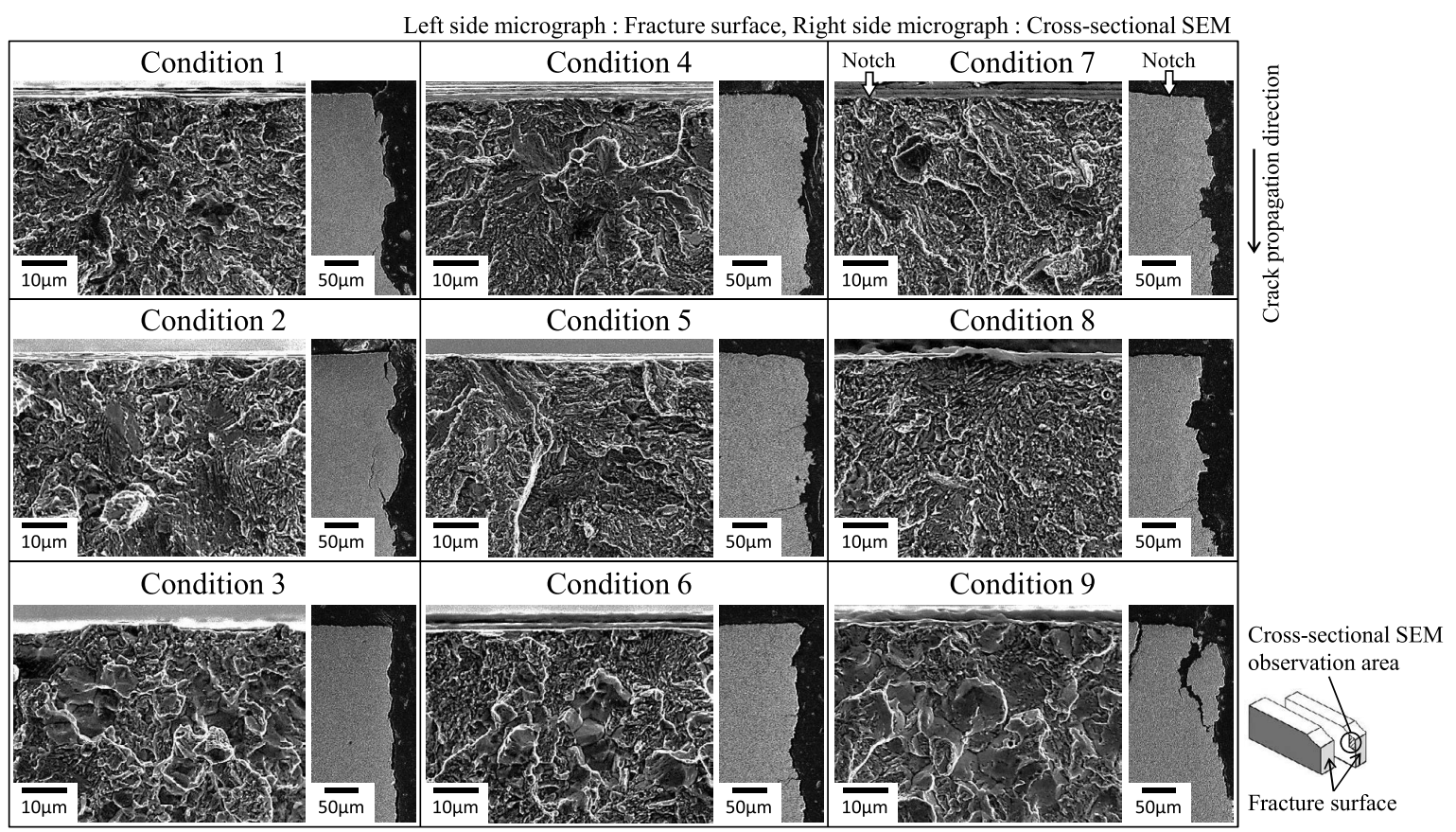

Fig. 9. Fractographs and cross-sectional SEM micrographs of the specimens prepared with various conditions after the Charpy impact test. 
treatments, the impact value for tempering (Conditions 4-6) was the highest, and decreased in the order of the quenching (Conditions 1-3) and the sub-zero treatment prior to tempering (Conditions 7-9).

As shown in Fig. 1, the $m$ value was the degree of inclination after the $P_{\max }$ in the load-displacement curve. In order to quantify the $m$ value under each condition, the inclination between the displacement of 0.08 and $0.30 \mathrm{~mm}$ from $P_{\max }$ was calculated. The displacement of $0.08 \mathrm{~mm}$ from $P_{\max }$ was determined as the position where the transition of the load-displacement curve changes from non-linear to linear. Focusing on $P_{\max }$ and the $m$ value in conjunction with the change in $T_{2}, P_{\max }$ increased with $T_{2}$ in conditions 1-6 (Figs. 6(a), 6(b)). The $m$ value also showed differences depending on $T_{2}$. By contrast, under conditions 7-9 (Fig. 6(c)), $P_{\max }$ increased with $T_{2}$, but the $m$ value did not depend on $T_{2}$ and showed almost the same inclination. Figure 8 shows the relation between each condition and $m$ value. The specimens for quenching conditions 1-3 showed a decrease in the $m$ value as $T_{2}$ increased, and those for tempering conditions 4-6 also showed a similar tendency. By contrast, those of the sub-zero treatment conditions 7-9 showed an almost constant $m$ value, irrespective of $T_{2}$.

\subsection{Fractography, Fracture Roughness, and Cross- sectional Micrograph after Charpy Impact Test}

Figure 9 shows fractographs and cross-sectional SEM micrographs in the direction perpendicular to the fracture surface. In the fractographs, the crack origin was observed at the notch bottom surface or the interior at $15 \mu \mathrm{m}$ from the notch surface. In the cross-sectional SEM micrographs, the fracture surface changed from uneven to smooth as $T_{2}$ increased for conditions $1-3$ and conditions 4-6. The tendency of this roughness change was consistent with the observation of the macro fracture surface. By contrast, the roughness of the conditions 7-9 specimens showed a large uneven fracture surface irrespective of the $T_{2}$. In particular, the condition 9 specimen showed multiple crack initiation and propagation, and separation of fragments was observed from the secondary crack branched off from the main crack. Figure 10 shows the relation between each condition and $S a$ in the fracture surface. Under conditions 1-3 and condi- tions 4-6, $S a$ decreased as $T_{2}$ increased. By contrast, under conditions 7-9, $S a$ increased with $T_{2}$. The change in $S a$ for each condition was similar to the tendencies of the change in the $m$ value (Fig. 8) and the unevenness of the crosssectional SEM micrographs (Fig. 9). Figure 11 shows the relation between the $m$ value and $S a$ separated at $T_{2}$. Under all conditions, the $m$ value increased with $S a$. Comparing the $m$ values under the same roughness indicated that conditions 1,4 , and 7 with low $T_{2}$ showed the highest $m$ value, and as $T_{2}$ increased the $m$ value decreased. Figure 12 shows the enlarged cross-sectional SEM micrographs of Fig. 9 for condition $1\left(T_{2}: 1043 \mathrm{~K}\right)$ and condition $3\left(T_{2}: 1143 \mathrm{~K}\right)$. In the condition 1 specimen, cracks showed transgranular propagation, although pro-eutectoid $\theta$ and quasi-lamellar $\theta$ remained in the undissolved state at the prior austenite grain boundaries (Fig. 12(a)). Therefore, the fracture surface under condition 1 in Fig. 9 was determined to be an transgranular fracture. The fracture surface for condition 1 and those for conditions 2, 4, 5, 7, and 8 were similar. Hence, the fracture surface of those conditions was considered to be an transgranular fracture. Furthermore, regarding the cross-sectional SEM micrograph in Fig. 12(a), undissolved quasi-lamellar $\theta$ of pearlite, which was the initial microstructure, existed at the position where crack branching occurred. When the crack propagation direction was perpendicular to the lamellar $\theta$ orientation (Figs. 12(b), 12(c)), cracks were branched at undissolved $\theta$. By contrast, when the crack propagation direction was parallel to the lamellar $\theta$ orientation (Fig. 12(d)), the crack propagated linearly along the lamellar $\theta$. Unlike in the condition 1 specimen, the crack propagated linearly in the condition 3 specimen with the undissolved $\theta$ decomposing and the formation of $\mathrm{C}$ solid solution progressing (Figs. 12(e), 12(f)) as $T_{2}$ increased. The amount of retained $\gamma$ in conditions 1 and 3 before the test was 15 vol\% and 34 vol\% respectively (Fig. 4 ), and the increase in $T_{2}$ indicated the decrease in undissolved $\theta$. Figure 13 shows the enlarged cross-sectional SEM micrographs of Fig. 9 under condition $8\left(T_{2}: 1093 \mathrm{~K}\right)$ and condition $9\left(T_{2}: 1143\right.$ $\mathrm{K})$. In the condition 8 specimen, cracks showed transgranular propagation, bending in the direction perpendicular to the propagation direction (Fig. 13(a), triangular arrow mark) was observed. This bending in the perpendicular direction

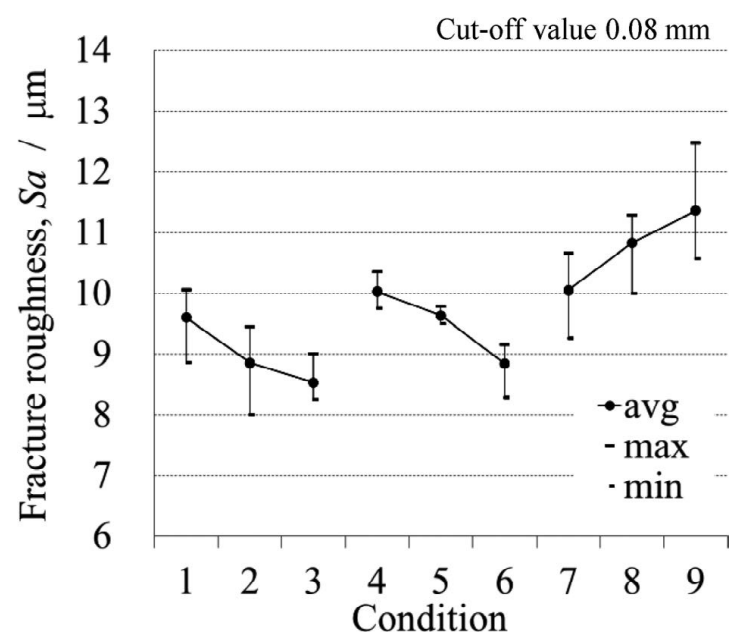

Fig. 10. Fracture roughness $(S a)$ near the crack origin in the Charpy impact test.

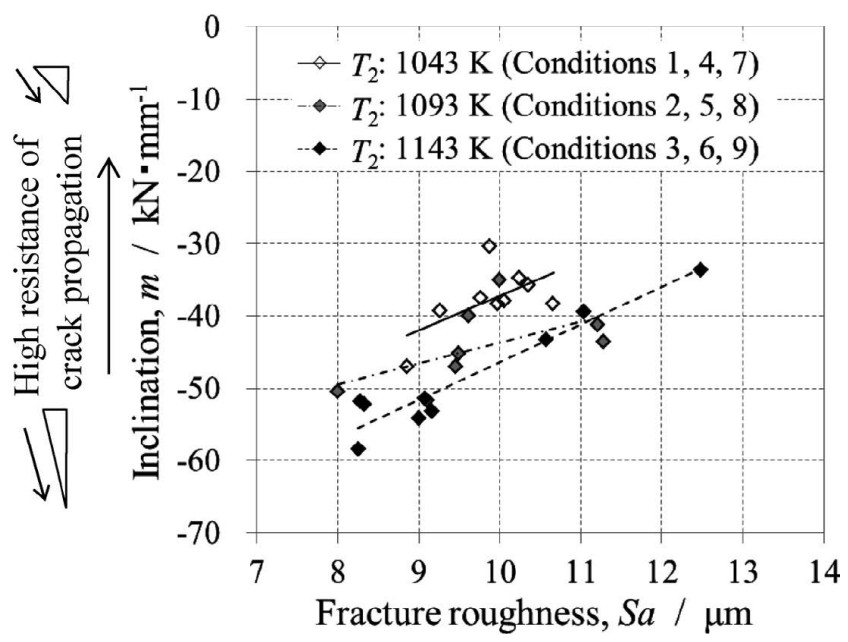

Fig. 11. Relation between the fracture roughness and the crack propagation resistance $(m)$. 


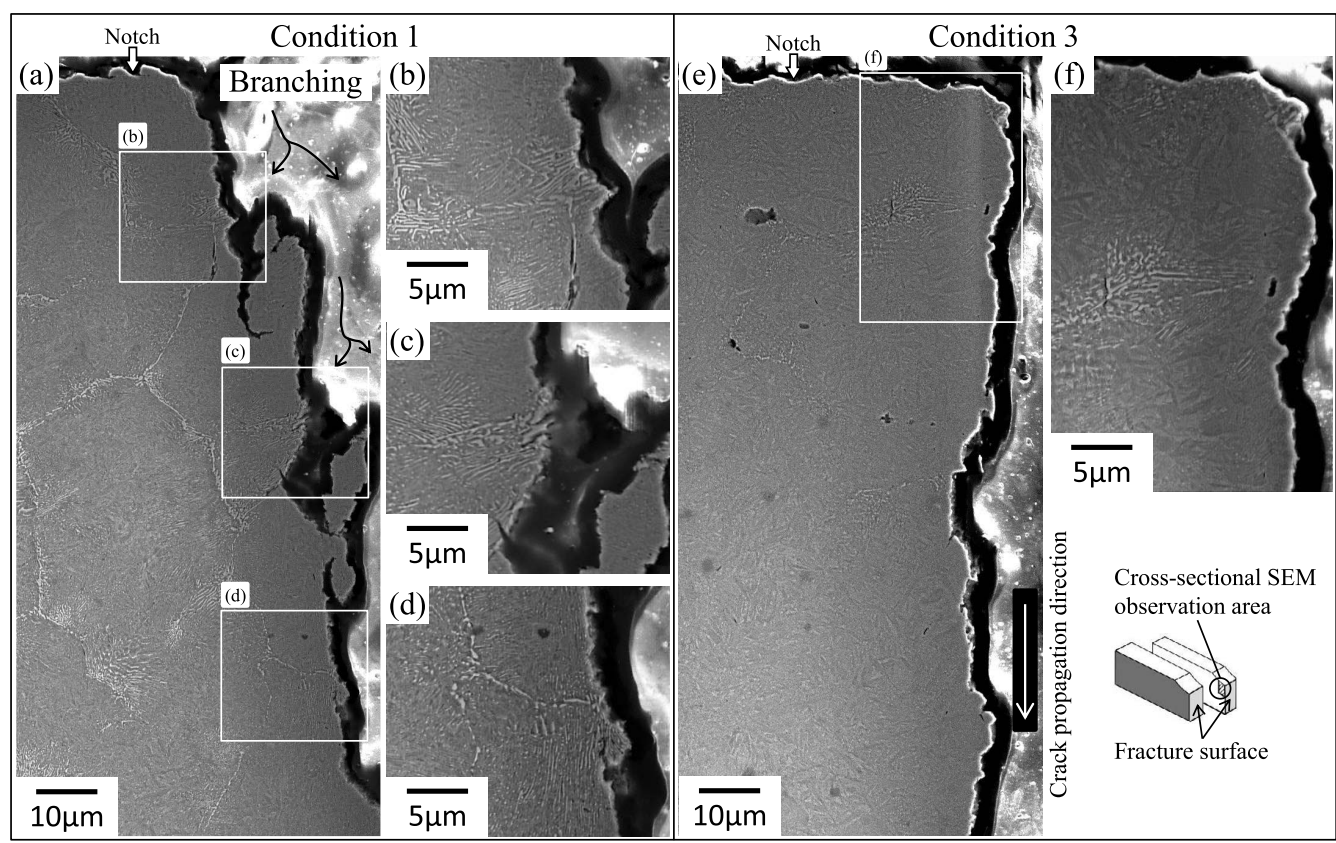

Fig. 12. (a), (e) Cross-sectional SEM micrographs at the crack propagation in the condition 1 and condition 3 specimens. (b), (c) High magnification micrographs with quasi-lamellar $\theta$ at the crack branch in (a). (d) High magnification micrograph with quasi-lamellar $\theta$ at the linear crack propagation in (a). (f) High magnification micrograph without quasi-lamellar $\theta$ at the linear crack propagation in (e).

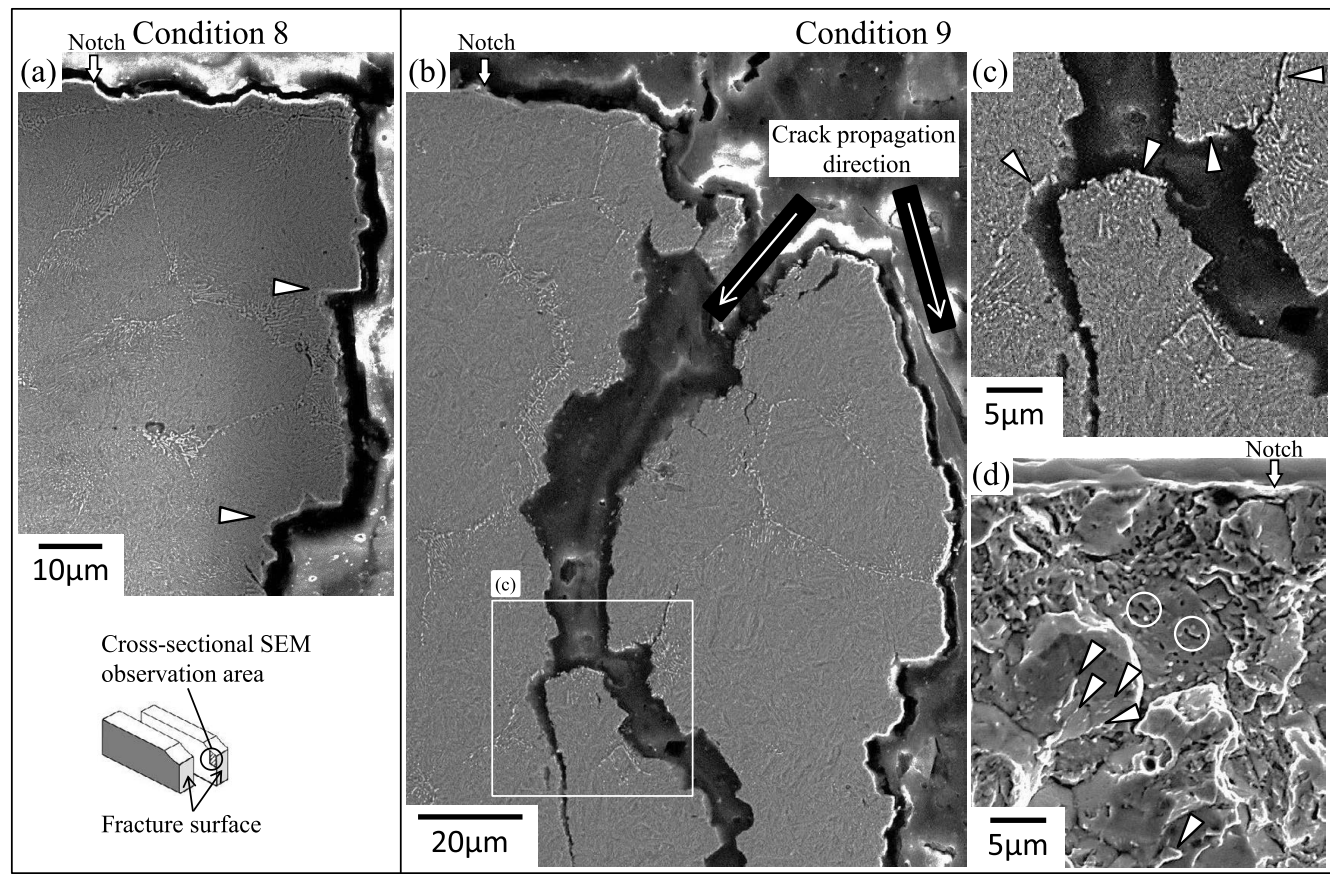

Fig. 13. (a), (b) Cross-sectional SEM micrographs at the crack propagation in the condition 8 and condition 9 specimens. (c) High magnification micrograph with the pro-eutectoid $\theta$ and the sub crack propagation in (b). (d) High magnification fractograph at the intergranular fracture of the condition 9 specimen in Fig. 9.

was frequently observed under the sub-zero treatment conditions (Fig. 9). In the condition 9 specimen, secondary cracks propagated along pro-eutectoid $\theta$ were observed (Fig. 13(c), triangular arrow mark). Figure 13(d) shows the enlarged micrograph of an intergranular fracture in the fractograph (Fig. 9, condition 9). On the intergranular fracture surface (triangular arrow mark in Fig. 13(d)), the $\theta$ with the same size as pro-eutectoid $\theta$ and quasi-lamellar $\theta$ observed in Fig. 13(c) could be seen. Also, the concaves (Fig. 13(d), circle mark) are considered to be caused by $\theta$ falling to the other broken piece. Therefore, the intergranular fracture surface for condition 9 shown in the fractograph (Fig. 9) was the division at the interface between $\theta$ and $\alpha$.

\section{Discussion}

Under low $T_{2}$ conditions, the crack branched when encountering undissolved $\theta$ oriented perpendicular to the propagation direction (Figs. 12(b), 12(c)). As $T_{2}$ increased, the crack linearly propagated without branching (Figs. 12(e), 
12(f)). Observation of crack branching and bending caused by microstructure was also common in previous researches. There were researches of crack bending along the prior austenite grain boundary ${ }^{8-13)}$ and crack bending and branching due to heterogeneous microstructure such as dual phase steel having $\alpha$ and $\alpha{ }^{1{ }^{14-18)}}$ Ohta et al. ${ }^{19)}$ observed the propagation path of the fatigue cracks using a specimen in which $\theta$ orientation was aligned by rolling the high-carbon steel. They reported that the crack showed bending and branching when the crack encountered $\theta$, resulting in the decrease of the stress intensity factor and suppression of crack propagation. Sudhakar et al. $^{20)}$ studied the fracture toughness of normalized and quenched-and-tempered specimens ( $773 \mathrm{~K}$ for 3.6 ks) using near-eutectoid steel. The quenched-and-tempered specimen showed higher resistance to crack propagation than the normalized specimen. That specimen followed from the tempered $\alpha^{\prime}$, which was reported to provide better toughness because finely-dispersed $\theta$ arrests crack propagation. Bloyer et al. ${ }^{21)}$ studied the fracture toughness of laminated $\mathrm{Nb} / \mathrm{Nb}_{3} \mathrm{Al}$ with different orientations of the arrester structure layered in the direction perpendicular to the crack propagation direction and the divider structure layered in the direction parallel to the crack propagation direction. They reported that the fracture toughness of the arrester structure was higher than that of the divider structure. Based on these previous studies, it was thought that the $\theta$ having the orientation observed in this study influenced crack propagation resistance. When the austenitizing temperature was between $A_{\mathrm{cm}}$ and $A_{1}$, the crack was affected by the arrest effect when it encountered undissolved $\theta$. This was thought to lower the propagation driving force and increase the $m$ value due to the crack branching. In Fig. 11, the reason for the highest $m$ value at the low austenitizing temperature in conditions 1,4 , and 7 was attributed to the arrest effect of the undissolved $\theta$. By contrast, as the austenitizing temperature between $A_{\mathrm{cm}}$ and $A_{1}$ increased, the decrement of the fraction of undissolved $\theta$ caused a decrease of the crack arrest effect. Hence, in Fig. 12, the crack of the condition 3 specimen propagated linearly without branching compared to the condition 1 specimen, and the $m$ value therefore decreased.

Under the sub-zero treatment conditions, crack propagation resistance showed an almost constant, high value irrespective of $T_{2}$ (Fig. 8). Figure 14 shows the relation between the amount of retained $\gamma$ before the test $\left(\gamma_{R}^{b}\right)$, the residual stress before the test $\left(\sigma^{b}\right)$, and the $m$ value. The $m$ value increased as the $\gamma_{R}{ }^{b}$ and $\sigma^{b}$ decreased. Regarding the effect of the retained $\gamma$ on residual stress, Panhans et al. ${ }^{22)}$ studied the fatigue strength of carburized AISI E9310 steel with two different levels of surface retained $\gamma$ and surface residual stress. The amount of retained $\gamma$ of the sub-zero treated specimen was reduced from 56 to $31 \mathrm{vol} \%$, and the residual stress had a compressive residual stress from -595 to $-760 \mathrm{MPa}$. As a result, fatigue strength was improved by the increase in crack propagation resistance. Studies on the effect of residual stress on toughness are limited compared to fatigue fracture studies. It has been reported that compressive residual stress can effectively contain crack propagation and improve fracture toughness, as measured by Shea, ${ }^{23)}$ Chaundhury, ${ }^{24)}$ Dejun et al. ${ }^{25)}$ and Xia et al. ${ }^{26)}$ In this study, as $\gamma_{R}{ }^{b}$ decreased, $\sigma^{b}$ tended to decrease (Fig. 14 ), and the crack propagation seemed to be suppressed. (a)

The number in ( ) means a condition.

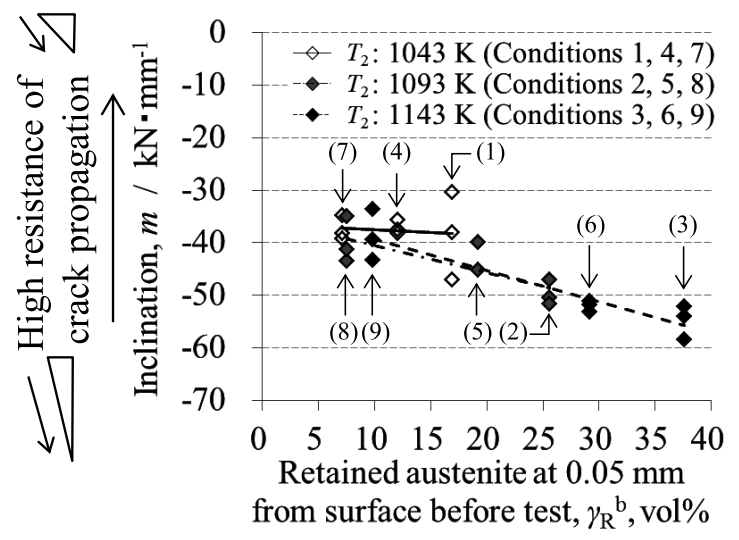

(b)

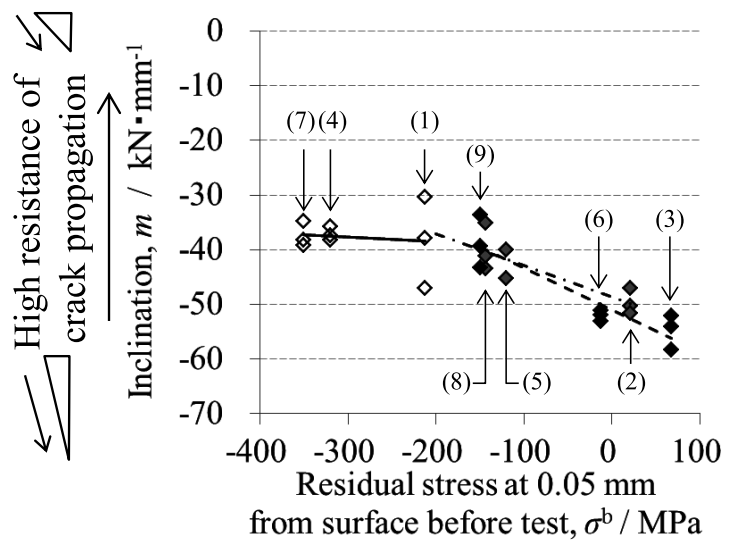

Fig. 14. Relation between the amount of retained austenite $\left(\gamma_{R}^{b}\right)$, the residual stress $\left(\sigma^{b}\right)$ before the Charpy impact test, and the crack propagation resistance $(m)$.

Although the conditions 8 and 9 specimens had lower compressive residual stress than the condition 7 specimen, these specimens showed almost the same $m$ value irrespective of $\sigma$. This means that the $m$ value cannot be explained only by the influence of residual stress under the sub-zero treatment conditions.

Focusing on the cross-sectional SEM microstructures, the conditions 8 and 9 specimens showed bending and branching during crack propagation (Fig. 13). These propagation behaviors resulted in an uneven fracture surface, which suggested that the crack propagation path was long. In particular, the condition 9 specimen showed the largest change in $m$ value with and without sub-zero treatment. Suresh et $a{ }^{27)}$ studied the beneficial effects of crack tip plasticity on fracture toughness and crack propagation resistance for branched cracks. They described how crack bending and branching could have a beneficial effect in terms of stress intensity factors. Their propagation behavior improved the fracture toughness as well as crack propagation resistance. Therefore, the bending and branching observed in this study seemed to have an effect that increases the crack propagation resistance. However, the detailed cause of bending and branching occurrence during crack propagation was not identified and will require future study.

\section{Conclusions}

In this study, we investigated the propagation behavior after the crack initiation using the instrumented Charpy 
impact test on case hardening steel subjected to a combined heat treatment of excess vacuum carburizing and subsequent induction hardening. We focused on the maximum load and the subsequent crack propagation behavior in the loaddisplacement curve, and the inclination of the curve was defined as the crack propagation resistance ( $m$ value). The effects of undissolved $\theta$ and residual stress on the $m$ value were investigated. From the results obtained in this study, following conclusions can be drawn.

(1) Decreasing the induction heating temperature from $1143 \mathrm{~K}$ (conditions 3 and 6) to $1043 \mathrm{~K}$ (conditions 1 and $4)$, which was in the two-phase $(\gamma, \theta)$ region between $A_{1}$ and $A_{\mathrm{cm}}$, increased the crack propagation resistance by around $30 \%$ on average in the quenching-only, and in the quenched-and-tempered specimens. By contrast, with the sub-zero treatment prior to the tempering, crack propagation resistance showed an almost constant, high value irrespective of the induction heating temperature.

(2) Under conditions with a low induction heating temperature, the crack was subjected to the arrest effect upon encountering undissolved pro-eutectoid $\theta$ or quasi-lamellar $\theta$ oriented perpendicular to the propagation direction. The arrest effect was thought to cause crack branching, and decrease propagation driving force, thereby indicating high crack propagation resistance. By contrast, as the induction heating temperature increased, the decrement of the undissolved $\theta$ caused the crack arrest effect to decrease. The results showed that the crack propagated linearly without branching, and that crack propagation resistance decreased.

(3) The sub-zero treated specimens showed a constant high crack propagation resistance irrespective of induction heating temperature. This factor cannot be explained only by residual stress. These specimens showed bending and branching propagation behavior during crack propagation, and they had a large fracture surface roughness. These propagation behaviors were thought to increase crack propagation resistance.

\section{Acknowledgements}

The authors would like to express their gratitude to Daido Special Steel Co., Ltd. for providing the steels for this experiment.

\section{REFERENCES}

1) K. Obayashi and K. Taguchi: 4th Int. Conf. on Gears, VDI-Verlag, Düsseldorf, (2010), 349.
2) K. Okada and K. Obayashi: Netsu Shori (J. Jpn. Soc. Heat Treat.), 56 (2016), 11 (in Japanese).

3) K. Okada, K. Obayashi, Y. Todaka and N. Adachi: Tetsu-to-Hagané, 105 (2019), 837 (in Japanese). https://doi.org/10.2355/tetsutohagane. TETSU-2018-166

4) T. Kobayashi, K. Takai and H. Maniwa: J. Jpn. Inst. Met., 30 (1966), 700 (in Japanese). https://doi.org/10.2320/jinstmet1952.30.7 700

5) ISO 25178-2: 2012, Geometrical product specifications (GPS) -- Surface texture: Areal -- Part 2: Terms, definitions and surface texture parameters.

6) ISO 4287: 1997, Geometrical Product Specifications (GPS) -- Surface texture: Profile method -- Terms, definitions and surface texture parameters.

7) Y. Tomota, N. Sekido, P. Xu, T. Kawasaki, S. Harjo, M. Tanaka, T. Shinohara, Y. Su and A. Taniyama: Tetsu-to-Hagané, 103 (2017), 570 (in Japanese). https://doi.org/10.2355/tetsutohagane.TETSU2017-045

8) K. Yoshikawa, T. Mizoguchi, S. Ohta and E. Sato: J. Soc. Mater. Sci., Jpn., 31 (1982), 265 (in Japanese). https://doi.org/10.2472/ jsms.31.265

9) K. Nakasa, X. Chen and H. Takei: J. Jpn. Inst. Met., 48 (1984), 1060 (in Japanese). https://doi.org/10.2320/jinstmet1952.48.11_1060

10) W. Wang and R. N. Singh: Mater. Sci. Eng. A, 251 (1998), 184. https://doi.org/10.1016/S0921-5093(98)00608-X

11) S. Kobayashi, T. Maruyama, S. Saito, S. Tsurekawa and T. Watanabe: J. Mater. Sci., 49 (2014), 4007. https://doi.org/10.1007/ s10853-014-8056-z

12) I. V. Ryakhovskikh, R. I. Bogdanov and V. E. Ignatenko: Eng. Fail. Anal., 94 (2018), 87. https://doi.org/10.1016/j.engfailanal.2018.07.036

13) T. Liu, S Xia Q Bai, B. Zhou, L. Zhang, Y Lu and T. Shoji: J. Nucl. Mater., 498 (2018), 290. https://doi.org/10.1016/j. jnucmat.2017.10.004

14) V. B. Dutta, S. Suresh and R. O. Ritchie: Metall. Mater. Trans. A, 15 (1984), 1193. https://doi.org/10.1007/BF02644714

15) K. Nakajima, S. Kamiishi, M. Yokoe and T. Miyata: ISIJ Int., 39 (1999), 486. https://doi.org/10.2355/isijinternational.39.486

16) K. Nakajima, T. Urabe, Y. Hosoya, S. Kamiishi, T. Miyata and N. Takeda: ISIJ Int., 41 (2001), 298. https://doi.org/10.2355/ isijinternational.41.298

17) M. Singh, A. Das, T. Venugopalan, K. Mukherjee, M. Walunj, T. Nanda and B. R. Kumar: Metall. Mater. Trans. A, 49 (2018), 463. https://doi.org/10.1007/s11661-017-4433-y

18) S. Li, Y. Zhang, L. Qi and Y. Kang: Int. J. Fatigue, 106 (2018), 49. https://doi.org/10.1016/j.ijfatigue.2017.09.018

19) S. Ohta, Y. Toyota and M. Saito: Tetsu-to-Hagané, 67 (1981), S549 (in Japanese).

20) K. V. Sudhakar and G. S. Murty: Bull. Mater. Sci., 21 (1998), 241. https://doi.org/10.1007/BF02744976

21) D. R. Bloyer, R. O. Ritchie and K. T. Venkateswara Rao: Metall. Mater. Trans. A, 29 (1998), 2483. https://doi.org/10.1007/s11661998-0220-0

22) M. A. Panhans and R. A. Fournelle: J. Heat Treat., 2 (1981), 54. https://doi.org/10.1007/BF02833074

23) M. M. Shea: SAE Technical Paper No. 780772, SAE International, Warrendale, PA, (1978), 1. https://doi.org/10.4271/780772

24) J. N. Chaudhury: J. Mater. Eng. Perform., 23 (2014), 152. https://doi. org/10.1007/s11665-013-0709-6

25) K. Dejun and Z. Lei: J. Mater. Eng. Perform., 23 (2014), 3695. https://doi.org/10.1007/s11665-014-1164-8

26) W. Xia, L. Li, Y. Wei, A. Zhao, Y. Guo, C. Huang, H. Yin and L. Zhang: Acta Mech. Sin., 32 (2016), 301. https://doi.org/10.1007/ s10409-015-0521-7

27) S. Suresh and C. F. Shih: Int. J. Fract., 30 (1986), 237. https://doi. org/10.1007/BF00019705 